\title{
EROSION DUE TO HIGH FLOW VELOCITIES: A DESCRIPTION OF RELEVANT PROCESSES
}

\author{
F. Bisschop ${ }^{1,2,3}$, P.J. Visser ${ }^{1}$, C. van Rhee ${ }^{1,2}$ and H.J. Verhagen ${ }^{1}$
}

\begin{abstract}
Convential models for the erosion of non-cohesive sediments overestimate the erosion rate induced by high flow velocities. These high flow velocities occur, for instance, in breaching of embankments or dunes (flow velocities up to $10 \mathrm{~m} / \mathrm{s}$ ) or in jetting sand with a trailing suction hopper dredger (30 to $60 \mathrm{~m} / \mathrm{s})$. At these very large flow velocities the erosion process is significantly influenced by the properties of the soil mass (non-cohesive particles). Governing parameters at higher flow velocities are dilatancy, permeability and the (un)drained shear strength of the soil. The sediment concentration in the water also influences the erosion process, especially in case of higher erosion rates. Based on the concept of Van Rhee $(2007,2010)$ a simple analytical formula is derived that gives a clear insight into the parameters influencing hindered erosion. The concept of hindered erosion is explained by two properties of granular soils: dilatancy and permeability. This implicates that the erosion behaviour of granular soils cannot be described by the behaviour of single particles alone. The properties of the whole soil mass should be considered in predicting erosion at higher flow velocities. Results of a large-scale breach experiment performed in 1994 in the Zwin Channel in the Netherlands (Visser, 1998) are analyzed to evaluate the formula.
\end{abstract}

Keywords: (hindered) erosion; granular sediments; breaching; jetting

\section{INTRODUCTION}

In the Netherlands the safety level of a dike is expressed in terms of risk. Risk is defined as the product of the probability of inundation (failure of the dike) and the expected damage caused by the inundation (Visser, 1998). It is necessary to model the inundation process of the polder in order to be able to estimate this damage (casualties, damage infrastructure, economic damage, etc.). The process of polder inundation depends heavily on the flow velocity through the breach and the development of the breach width in time. The flow velocity in a breach can range up to approximately $10 \mathrm{~m} / \mathrm{s}$. Due to these large flow velocities, the application of conventional sediment erosion formulae, like that of Van Rijn (1993), in breach models leads to significant overestimations of the breach growth.

The same difference is encountered in dredging practice. Trailing suction hopper dredgers extract sand from the sea bed for reclamation purposes. A suction head is trailed over the sea bed and the granular sediment is loosened using water jets. Typical flow velocities are around 30 to $60 \mathrm{~m} / \mathrm{s}$ (Van Rhee, 2007, 2010). As in the breaching process, the conventional erosion functions also overestimate the erosion rate during jetting.

\section{TRADITIONAL EROSION FORMULA}

Sediment erosion formulae like that of Van Rijn (1993) are basically pick-up functions of single particles. Particle movement will occur when the instantaneous fluid force on a particle exceeds the instantaneous resisting force related to the submerged particle weight and the friction coefficient. Incipient motion, erosion rate and sediment transport are related to the mobility parameter (or Shields parameter) $\theta$ :

$$
\theta=\frac{\tau_{b}}{\left(\rho_{s}-\rho\right) g D}
$$

in which $\tau_{b}=$ bed-shear stress $\left[\mathrm{N} / \mathrm{m}^{2}\right], \rho=$ density of water $\left[\mathrm{kg} / \mathrm{m}^{3}\right], \rho_{s}=$ density of sediment $\left[\mathrm{kg} / \mathrm{m}^{3}\right], g=$ acceleration of gravity $\left[\mathrm{m} / \mathrm{s}^{2}\right]$ and $D=$ particle diameter of granular sediment $[\mathrm{m}]$.

\footnotetext{
${ }^{1}$ Section Hydraulic Engineering, Faculty Civil Engineering and Geosciences, Delft University of Technology, Stevinweg 1, 2628 CN Delft, The Netherlands

2 Section Offshore and Dredging Engineering, Faculty Mechanical, Maritime and Materials Engineering, Delft University of Technology, Mekelweg 2, 2628 CD Delft, The Netherlands

${ }^{3}$ Arcadis, Lichtenauerlaan 10, 3062 ME Rotterdam, The Netherlands
} 


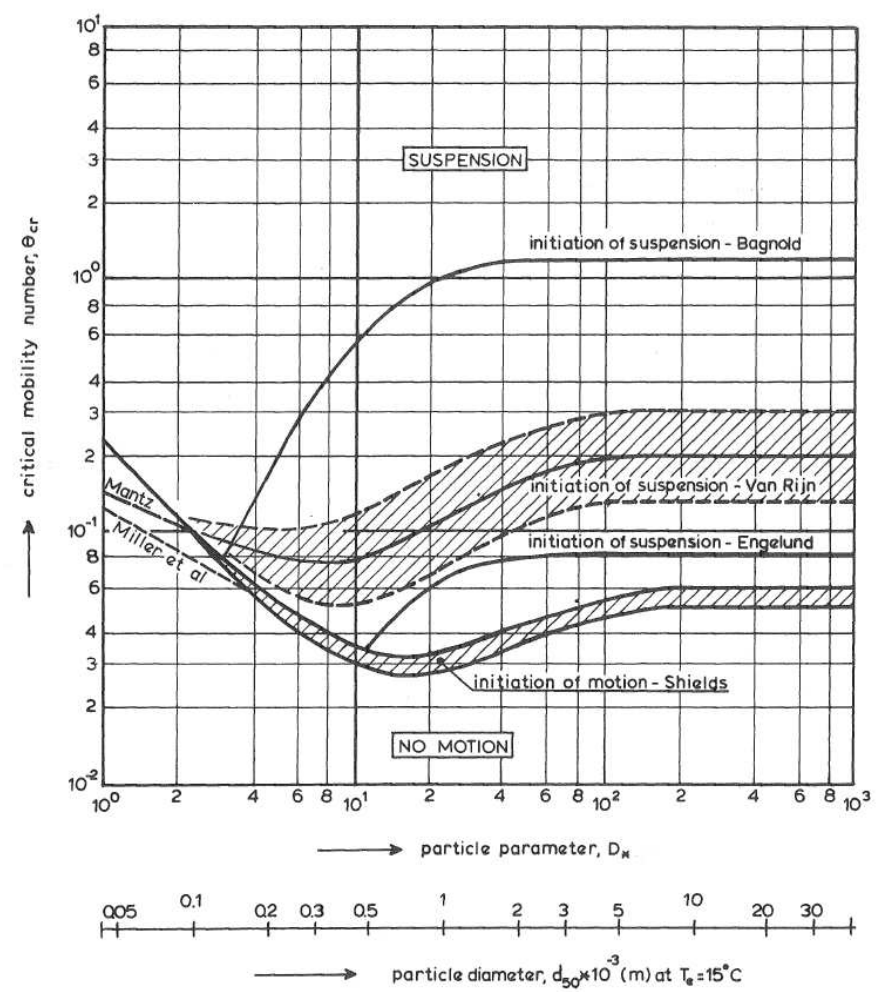

Figure 1. Incipient motion and suspension for a flow over a plane bed (Van Rijn, 1993)

Van Rijn (1993) expresses the critical Shields parameter $\theta_{c r}$ for incipient motion:

$$
\theta_{c r}=\frac{\tau_{b, c r}}{\left(\rho_{s}-\rho\right) g D_{50}}
$$

as function of the dimensionless particle diameter $D *$ :

$$
D_{*}=\left[\frac{\Delta g}{v^{2}}\right]^{1 / 3} D_{50}
$$

in which $\tau_{b, c r}=$ critical bed-shear stress $\left[\mathrm{N} / \mathrm{m}^{2}\right], D_{50}=$ median particle diameter of granular sediment $[\mathrm{m}], \Delta=$ relative density difference $=\left(\rho_{s}-\rho\right) / \rho[-]$ and $v=$ kinematic viscosity of water $\left[\mathrm{m}^{2} / \mathrm{s}\right]$, see Fig 1.

Van Rijn (1993) performed experiments to determine the pick-up rate of particles in the range of 0.130 to $1.50 \mathrm{~mm}$. Tests were performed with mean flow velocities in the range of 0.5 to $1.0 \mathrm{~m} / \mathrm{s}$. Analysis of the experimental data (see Fig. 2) has yielded the following empirical pick-up function:

$$
E=0.00033 \rho_{s}\left[\Delta g D_{50}\right]^{0.5} D_{*}^{0.3} T^{1.5}
$$

with

$$
T=\frac{\tau_{b}-\tau_{b, c r}}{\tau_{b, c r}}=\frac{\theta-\theta_{c r}}{\theta_{c r}}
$$

where $E=$ pick-up rate in mass per unit area and time $\left[\mathrm{kg} / \mathrm{sm}^{2}\right]$. 


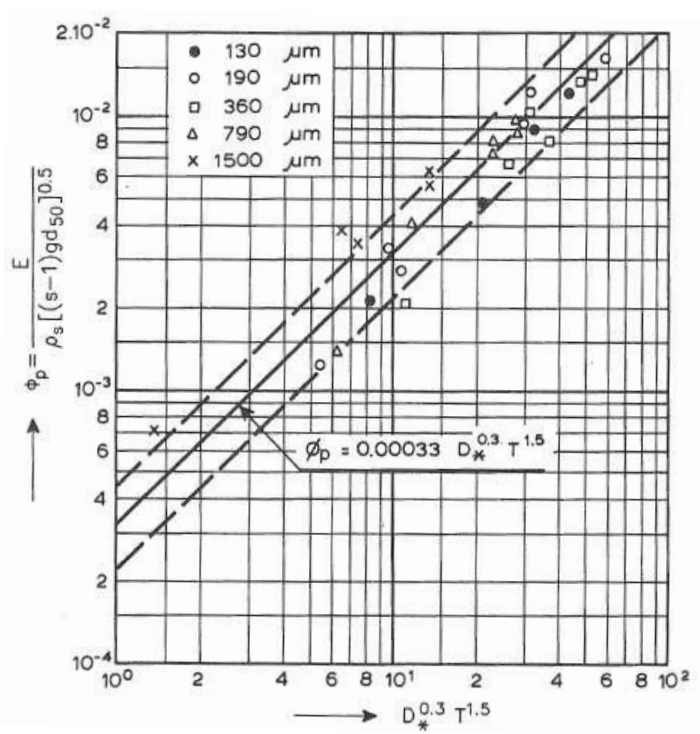

Figure 2. Empirical pick-up function of Van Rijn (1993)

The erosion rate $v_{e}$ in $[\mathrm{m} / \mathrm{s}]$ is given by

$$
v_{e}=\frac{E}{\rho_{s}\left(1-n_{0}\right)}
$$

where $n_{0}=$ in-situ porosity [-].

\section{HINDERED EROSION}

The theory of hindered erosion is based on the assumption that the erosion is hindered by the properties of the soil mass, especially taking place at higher flow velocities, see Van Rhee (2007, 2010). To understand the theory of hindered erosion, two properties of a granular soil should be explained: dilatancy and permeability.

\section{Dilatancy}

At relatively low flow velocities grains are picked up grain by grain. When flow velocity and erosion rate increase layers of grains are picked up at a time. The top layer of the sand-bed is subjected to shear (see Van Rhee, 2007, 2010). During shearing the arrangement of the grains will change to enhance horizontal en vertical deformation. If the grains are loosely packed (as shown in Fig. 3), porosity decreases while shearing. This is called contractant behaviour. Normally sand is densely packed, as shown in Fig. 4. During shearing the grains have to move upwards in order to enhance horizontal displacements, then the porosity of the sand increases. The increase in volume needs to be compensated by the flow of water to the increased pore volume. This happens only if the pore pressure decreases in the sheared zone introducing a hydraulic gradient. The hydraulic gradient pushes the top layer on the bed and hinders erosion. This gradient will increase with the erosion rate and decreases with the permeability of the sand.

\section{Permeability}

The following three characteristics influence the permeability of fully saturated granular soils (Lambe and Whitman, 1969): particle size (distribution), porosity, composition (mineralogy).

Particle size. Particle size is highly influencing the permeability because the smaller the soil particles the smaller the voids. The voids form the flow channels, thus smaller voids lead to lower permeability. Already about a century ago, Hazen developed the following empirical formula for the prediction of the 


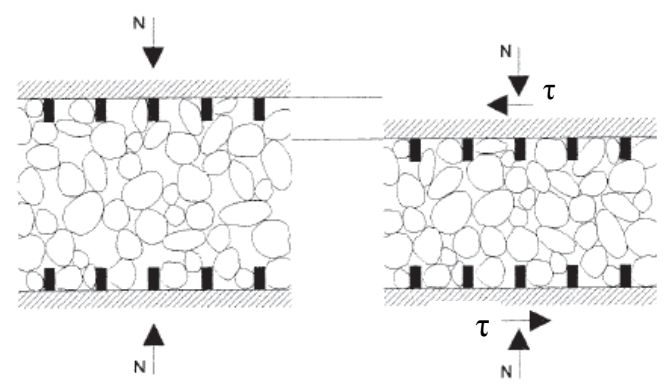

Figure 3. Decrease of porosity during shearing of loosely packed sand: contractant behaviour (CROW, 2004)

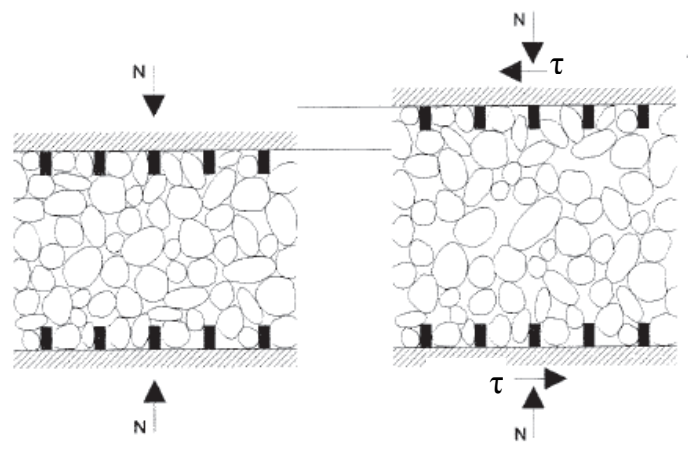

Figure 4. Increase of porosity during shearing of densely packed sand: dilatant behaviour (CROW, 2004)

permeability of saturated sands (see geotechnical textbooks):

$$
k=m D_{10}^{2}
$$

in which $k=$ permeability $[\mathrm{m} / \mathrm{s}], D_{10}=$ grain size at which $10 \%$ of the soil weight is finer [m], $m=$ constant being approximately $10^{4}$ (but wide ranges for this constant have been reported, see Carrier, 2003). Eq. (7) holds the assumption that the distribution of particle sizes is spread enough to prevent the smallest particles from moving under the seepage force of the flowing water. If the flow washes out the fines, the permeability increases with the duration of the flow.

Porosity. Another factor but not highly influencing permeability is the porosity $n_{0}$ (void ratio and insitu density are related parameters). A semi-empirical, semi-theoretical expression describing the permeability of porous media is the well known Kozeny-Carman equation. With the inclusion of the effect of the angularity of grains, this equation reads (see geotechnical textbooks):

$$
k=\frac{g}{v} \frac{1}{K_{0} S_{v}^{2} f} \frac{n_{0}^{3}}{\left(1-n_{0}\right)^{2}}
$$

in which $v=$ kinematic viscosity water $\left.\left[\mathrm{m}^{2} / \mathrm{s}\right)\right], n_{0}=$ porosity [-], $K_{0}=$ Kozeny-Carman constant $[\approx 5]$, $S_{v}=$ specific grain surface $\left[\mathrm{m}^{2} / \mathrm{m}^{3}\right], f=$ angularity factor of Loudon $[1.1-1.4]$. Since the specific grain surface $S_{v}$ is inversely proportional to the grain size, Eq. (7) and (8) can be combined (see also Bear, 1972, and Batu, 1998) to give

$$
k=C_{k} \frac{g}{v} D_{10}^{2} \frac{n_{0}^{3}}{\left(1-n_{0}\right)^{2}}
$$

in which $C_{k}$ is a coefficient mainly depending on the particle size distribution and the angularity of the grains. Thus, an increase of the porosity is related to an increase of the permeability: the permeability of 
a rather loosely packed granular material is approximately 3 times higher than of a densely packed granular material.

Composition/mineralogy. The last effect is the amount and mineralogy of the fines (particle size $\leq 2$ $\mu \mathrm{m})$. Smaller grains in between larger grains decrease the effective porosity and therefore the permeability (see Fig. 5). If the particles between the larger grains are clay particles the permeability decreases significant. This is the result of the ability of clay particles to bind water. Due to their capacity in binding water the clay particles fill a relatively large volume in relation to (inert) quartz particles of similar size. The amount of water which is bound depends on the mineralogy of the clay particles. A useful index to characterize the bounding capacity of water and resulting assemblage of soil particles are the Atterberg limits. The Atterberg limits for a soil are related to the amount of water that is attracted to the surface of the soil particles and therefore they determine the total volume of the clay particles and bounded water. Based on this knowledge Skempton (see Lambe and Whitman, 1969) defined a quantity called activity:

$$
A=\frac{P I}{\% \leq 2 \mu m}
$$

in which $A=$ activity [-] and $P I=$ plasticity index [\%].

The plasticity index and amount of the clay fraction $(\leq 2 \mu \mathrm{m})$ determine the activity and therefore the effect of the clay fraction on the permeability.

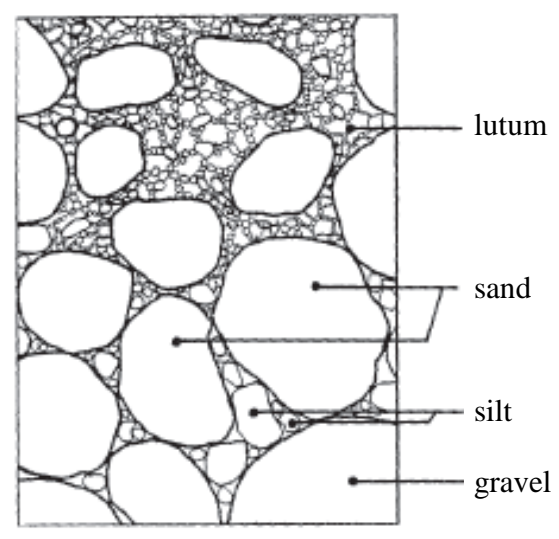

Figure 5. Soil fabric of granular material containing fines (CROW, 2004)

\section{EROSION FORMULA FOR HIGH VELOCITIES}

Van Rhee $(2007,2010)$ derived an erosion formula that includes the effect of hindered erosion. The model is based on the effect of dilatancy and permeability of the soil. At relatively low flow velocities the grains are picked up grain by grain by the current. At increasing flow velocities and subsequent erosion rates, the top layer of the soil is sheared. As a result of shearing the grains show dilatant behaviour when the soil is packed higher than its critical density, being normally the case. The porosity of the top layer increases and water has to flow into the sheared zone. This causes a hydraulic gradient that pushes the top layer on the bed and "hinders" erosion. The hydraulic gradient (i) over the top layer is

$$
i=\frac{v_{e}}{k} \frac{n_{i}-n_{0}}{1-n_{i}}
$$

in which $n_{i}=$ porosity sheared layer [-]. 
A hydraulic gradient in a sandy slope has an effect on the stability of the slope in the material (see Van Rhee and Bezuijen, 1992). An inward directed hydraulic gradient exerts an extra force on the soil particles, an outward directed hydraulic gradient a lower force. An inward flow in the slope increases the stability while an outward flow is decreasing the stability. This behaviour can be compared with the effect of dilatancy. Dilatancy causes an extra inward hydraulic gradient on the soil particles increasing the stability, or better increasing the resistance to erosion.

Practically this can be explained by a fictitious higher critical Shields parameter $\left(\theta_{c r}^{*}\right)$ that includes the effect of the inward hydraulic gradient. Considering the soil mass as a continuum, Van Rhee (2007, 2010) derived for this fictitious parameter:

$$
\theta_{c r}^{*}=\theta_{c r}\left(\frac{\sin (\varphi-\beta)}{\sin (\varphi)}+\frac{i}{\Delta\left(1-n_{0}\right)}\right)
$$

in which $\varphi=$ angle of friction granular material/soil particles $\left[^{\circ}\right]$ and $\beta=$ angle of slope $\left[^{\circ}\right]$.

Substitution of (11), the hydraulic gradient $(i)$ caused by dilatancy and the resulting flow of water, into (12) gives the following criterion:

$$
\theta_{c r}^{*}=\theta_{c r}\left(\frac{\sin (\varphi-\beta)}{\sin (\varphi)}+\frac{v_{e}}{k} \frac{n_{i}-n_{0}}{1-n_{i}} \frac{1}{\Delta\left(1-n_{0}\right)}\right)=\left(\frac{\sin (\varphi-\beta)}{\sin (\varphi)}+\delta \frac{v_{e}}{k}\right) \theta_{c r}
$$

in which

$$
\delta=\frac{n_{i}-n_{0}}{1-n_{i}} \frac{1}{\Delta\left(1-n_{0}\right)}
$$

Eq. (13) includes the effect of hindered erosion. Eq. (5) becomes with $\theta_{c r}^{*}$ for $\theta_{c r}$ :

$$
T=\frac{\theta-\theta_{c r}^{*}}{\theta_{c r}^{*}}
$$

For relatively high erosion rates, i.e. for flow velocities of more than $4 \mathrm{~m} / \mathrm{s}$ and relative erosion rates $\left(v_{e} / k\right)$ of more than 40 the following simplifications can be made:

$$
\begin{gathered}
\theta-\left(\frac{\sin (\varphi-\beta)}{\sin (\varphi)}+\delta \frac{v_{e}}{k}\right) \theta_{c r} \approx \theta \approx \theta-\theta_{c r} \\
\left(\frac{\sin (\varphi-\beta)}{\sin (\varphi)}+\delta \frac{v_{e}}{k}\right) \theta_{c r} \approx \delta \frac{v_{e}}{k} \theta_{c r}
\end{gathered}
$$

Consequently, Eq. (15) can be written as

$$
T=\frac{\theta-\left(1+\delta \frac{v_{e}}{k}\right) \theta_{c r}}{\left(1+\delta \frac{v_{e}}{k}\right) \theta_{c r}} \approx \frac{\theta-\theta_{c r}}{\delta \frac{v_{e}}{k} \theta_{c r}}
$$

Combining (4), (5), (6) and (13) gives an equation in which the erosion rate $v_{e}$ is present in both sides of the equation (Van Rhee, 2007, 2010). The simplification according to (16), (17) and (18) leads to 


$$
v_{e}^{5}=\alpha^{2} D_{*}^{0.6}\left(\frac{\theta-\theta_{c r}}{\theta_{c r}}\right)^{3}\left(\frac{k}{\delta}\right)^{3}
$$

in which

$$
\alpha=0.00033 \frac{\sqrt{\Delta g D_{50}}}{1-n_{0}}
$$

The error due to the simplification is less than $10 \%$ for above mentioned values of the flow velocity and $v_{e} / k$ (see Fig. 6). For jetting in dredging practice (flow velocities of more than $30 \mathrm{~m} / \mathrm{s}$ ) the error is negligible $(<1 \%)$.

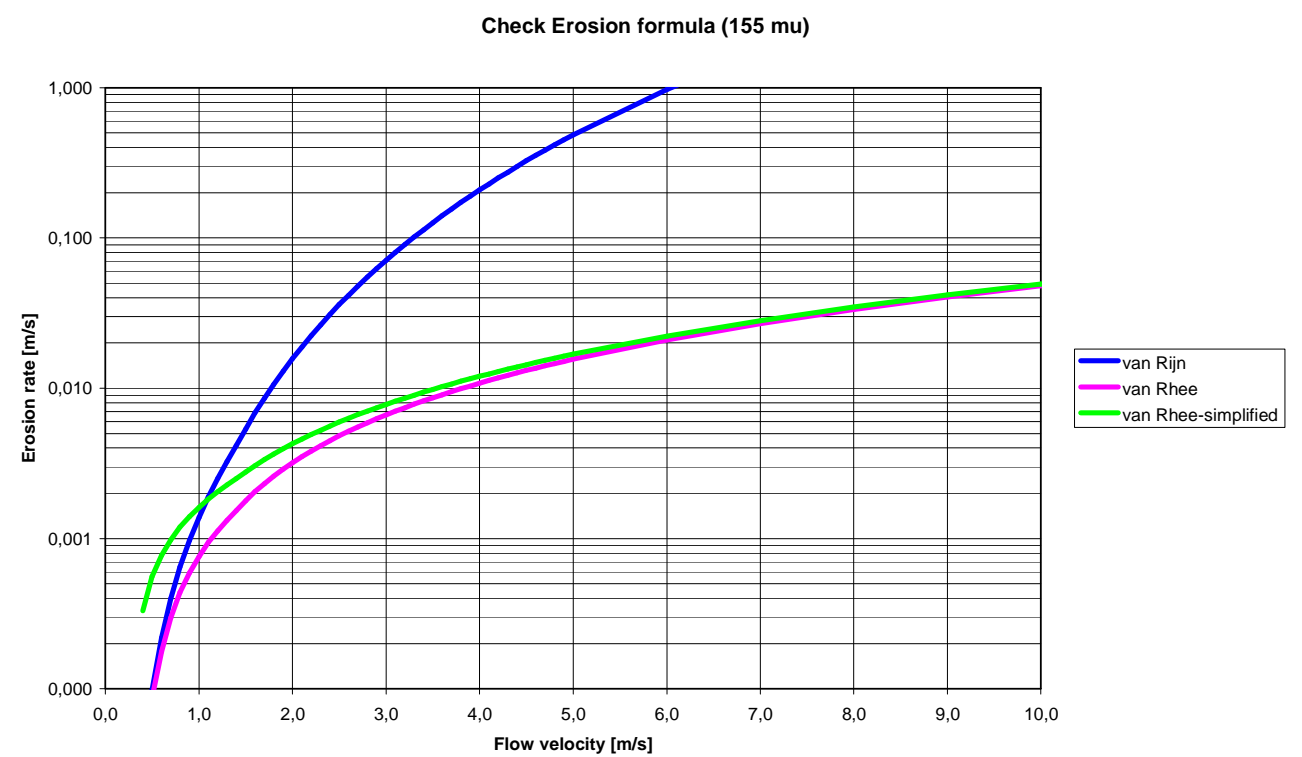

Figure 6. Check simplification

The factor $\delta$ defined in Eq. (14) is the dilatancy factor. A higher factor means that the porosity of the granular material needs to increase more to enhance shearing of the layer, causing a higher inward gradient during erosion.

Eq. (19) gives a clear understanding of the mechanism of hindered erosion:

- a lower permeability causes a lower erosion rate: the lower the permeability the higher the extra downward force due to the extra hydraulic gradient;

- for a material with a relatively large in-situ porosity (relatively small $\delta$ ), a relatively small increase of the porosity is necessary, resulting in less hindered erosion and thus a larger erosion rate;

- an increase of the critical Shields parameter leads to a decrease in erosion rate.

\section{EVALUATION WITH DATA OF ZWIN'94-EXPERIMENT}

To evaluate the theory, erosion data are necessary. No specific data are available in the literature of erosion rates induced by water jets (dredging at relatively high erosion rates and/or dredging of granular material with a relatively low permeability). To overcome this problem data were used of a large-scale dike breach experiment (Zwin'94 experiment). The Zwin'94 experiment was performed in 1994 in the Zwin Channel, a tidal inlet at the Dutch-Belgian border connecting the nature-reserve "Het Zwin" with the North Sea. The very good data of this field experiment have been used to calibrate a model for breach development (see Visser, 1998). 


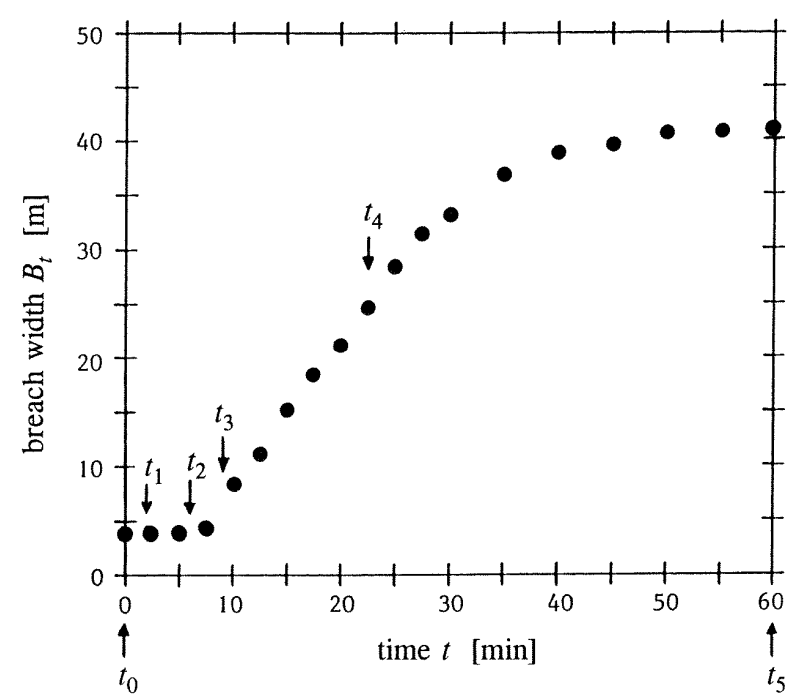

Figure 7. Growth of breach width $B_{t}$ observed in Zwin'94 experiment (Visser, 1998)

A sand-dike was built with local sand from the Zwin Channel and the beach. The Zwin Channel was closed off completely by the sand-dike. Just before high tide a small pilot channel was made in the crest of the sand-dike to ensure breaching near the middle of the Zwin Channel. Fig. 7 shows the observed growth of the breach width (measured at the top of the sand-dike). These data are used to evaluate the above presented model. On the basis of the data shown in Fig. 7 the vertical erosion rate was determined:

$$
v_{e}=\frac{1}{2} \frac{\mathrm{d} B_{t}}{\mathrm{~d} t} \tan (\gamma)
$$

in which $B_{t}=$ breach width at the top of the dike $[\mathrm{m}]$ and $\gamma=$ angle of the side slopes of the breach $\left[^{\circ}\right]$.

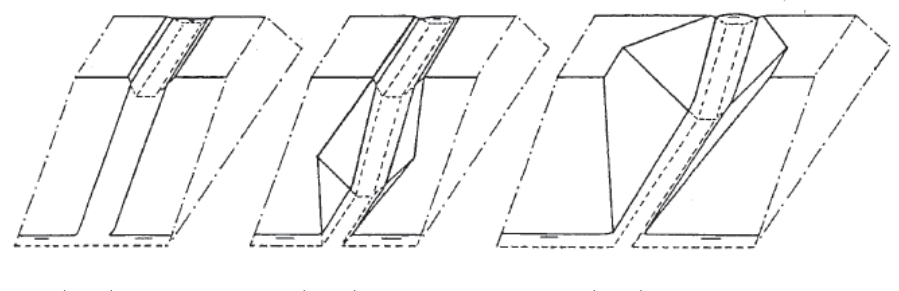

$$
t=t_{0} \quad t=t_{1} \quad t=t_{2}
$$

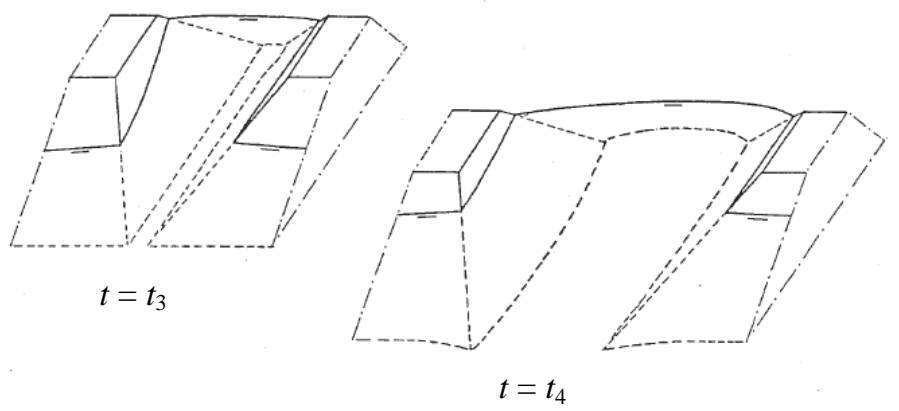

Figure 8. Schematic illustration of breach growth in a sand-dike (Visser, 1998) 
For the data only results are used of the breach growth in phase 4 (between $t_{3}$ and $t_{4}$ ) and phase 5 (after $t_{4}$ ) (Visser, 1998). These phases follow phase 3 at the end of which (at $t_{3}$ ) the breach has grown through the whole dike and has reached the base of the dike. In phase 4 the flow through the breach is critical and the erosion process is rather constant in time. In phases 4 and 5 the erosion of the breach takes mainly place by vertical erosion of the side slopes of the breach (see Fig. 8).

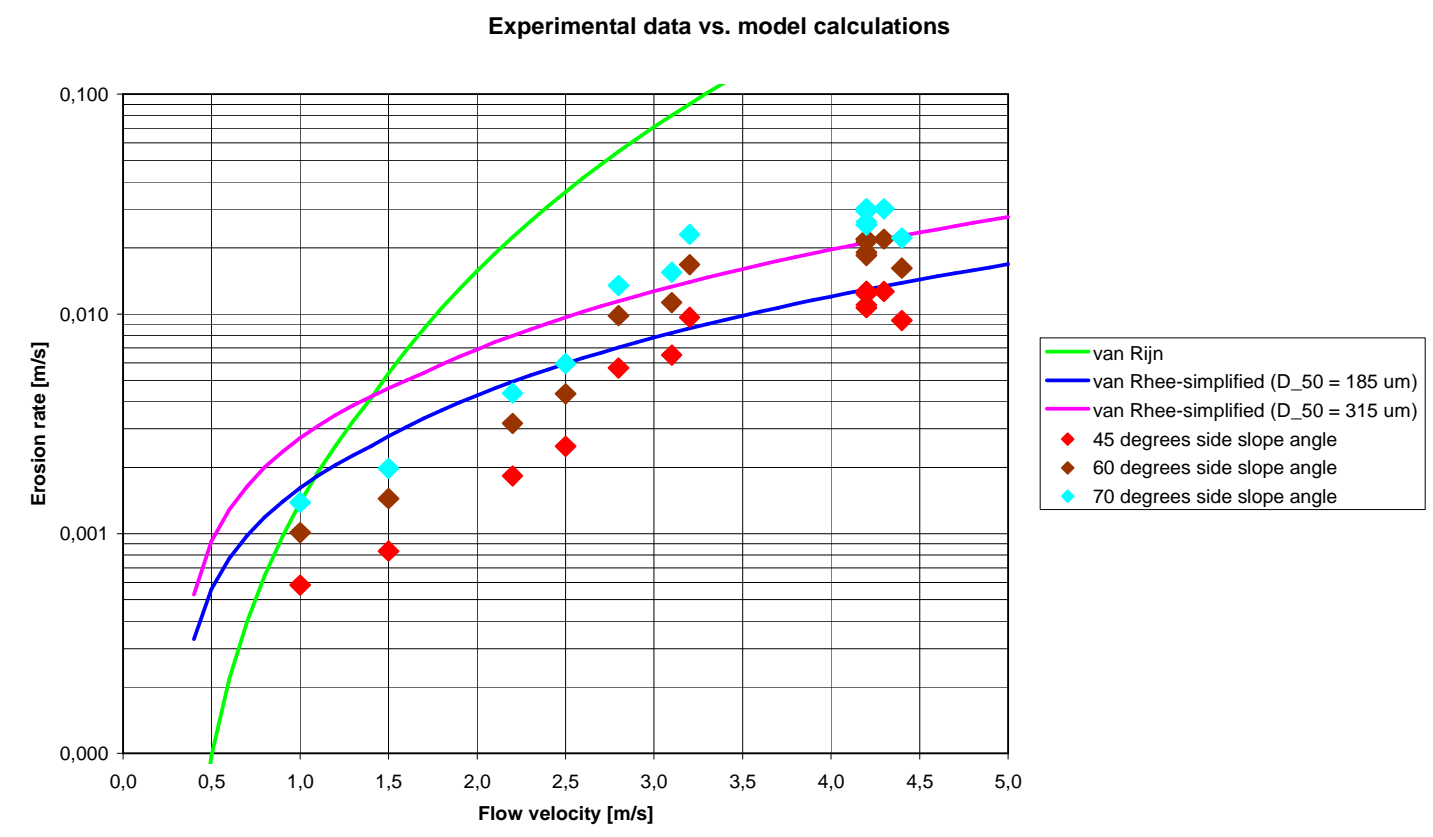

Figure 9. Erosion rates for Zwin'94 Experiment

On the basis of these results the erosion rate was calculated from the observed development of the breach width at the crest of the dike and compared with the flow velocity through the breach (see Fig. 9). These observed erosion rates are compared with the erosion rates calculated with the simplified Van Rhee model. Two components of the data set of the Zwin'94 experiment are rather unknown:

- grain size of the sand: the sand-dike was built with material from the Zwin Channel and from the beach. These materials showed large differences in grain size $\left(D_{50}=185\right.$ and $\left.315 \mu \mathrm{m}\right)$. Calculations of the erosion rates for both materials were made (Fig. 9);

- side slope angle of the breach: to determine the vertical erosion rate from the experimental data the side slope angle should be known. This angle was not measured in the Zwin'94 experiment, but both photos and videos taken during the experiment show that this angle was rather large, say about $60^{\circ}$. The sensitivity of the calculated erosion rate as function of the slope angle was determined for three side slope angles (see Fig. 9).

Fig. 9 shows that the erosion model of Van Rijn (1993) overestimates the erosion rate at flow velocities of more than $1 \mathrm{~m} / \mathrm{s}$ and values of $v_{e} / k$ being larger than 5 . At higher flow velocities the simplified Van Rhee model gives better agreement with the data. Especially this model gives a rather good prediction of the erosion rates in phase 4, while the model overestimates the erosion rates in phase 5 (flow velocity smaller than $3 \mathrm{~m} / \mathrm{s})$. For flow velocities smaller than $3 \mathrm{~m} / \mathrm{s}$ the model of Van Rhee $(2007,2010)$ should be used. Other possible causes for these differences could be the variable nature of the material used in the sand-dike and/or changes in the side slope angle during the breach process. 


\section{CONCLUSIONS}

Erosion of granular materials is not only influenced by the properties of the single particles (grain diameter $D_{50}$ and density $\rho_{s}$ ) but at higher flow velocities (higher than $1.0 \mathrm{~m} / \mathrm{s}$ ) the erosion process is significantly influenced by the properties of the soil mass. Governing parameters at higher flow velocities are dilatancy, permeability and the (un)drained shear strength of the soil mass. Based on the concept presented by Van Rhee $(2007,2010)$ a simple analytical formula is derived for hindered erosion, in which the erosion process is also influenced by two extra properties of the soil mass: dilatancy and permeability. The model shows that the erosion rate is directly related to the permeability $\left(k^{0.6}\right)$ and the amount of dilatancy. A relatively high volume increase during shearing (the higher the amount and factor of dilatancy) causes a relatively low erosion rate.

The model was compared with the data of a large-scale breach experiment performed in 1994 in the Zwin-channel. The agreement between model predictions and experimental data is rather good, especially for high flow velocities (higher than $4 \mathrm{~m} / \mathrm{s}$ ). This makes the model useful, especially for dredging.

\section{ACKNOWLEDGEMENT}

The financial support of the SSB (Stichting Speurwerk Baggertechniek, which includes Royal Boskalis Westminster Dredging BV and Van Oord Dredging and Marine Contractors BV), IHC Holland BV and the Dr. Ir. Cornelis Lely Foundation (Rijkswaterstaat) is gratefully acknowledged.

\section{REFERENCES}

Batu, V. 1998. Aquifer Hydraulics; A Comprehensive Guide to Hydrogeologic Data Analysis, John Wiley \& Sons, New York, NY, USA.

Bear, J. 1972. Dynamics of Fluids in Porous Media, American Elsevier, New York, NY, USA.

Carrier, W.D. 2003. Goodbye, Hazen; Hello, Kozeny-Carman, Journal of Geotechnical and Environmental Engineering, ASCE, vol. 129, no. 11, pp. 1054-1056.

CROW, 2004. Handboek Zandboek (in Dutch), CROW, Ede, the Netherlands.

Lambe, T.W. and R.W. Whitman. 1969. Soil Mechanics, John Wiley \& Sons, New York, NY, USA.

Van Rhee, C. 2007. Erosion of granular sediments at high flow velocity, Hydrotransport 17, The $17^{\text {th }}$ International Conference on the Hydraulic Transport of Solids, Cape Town, South Africa.

Van Rhee, C. 2010. Sediment entrainment at high flow velocity, Journal of Hydraulic Engineering, ASCE, vol. 136, no. 9, pp. 572-582.

Van Rhee, C. and A. Bezuijen. 1992. Influence of seepage on stability of sandy slope, Journal of Geotechnical Engineering, ASCE, vol. 118, no. 8, pp. 1236-1240.

Van Rijn, L.C. 1993. Principles of Sediment Transport in Rivers, Estuaries and Coastal Seas, Amsterdam, the Netherlands.

Visser, P.J. 1998. Breach growth in sand-dikes, PhD thesis, Delft University of Technology, Delft, the Netherlands. 